\title{
Suicide attempts and non-suicidal self-harm: national prevalence study of young adults
}

Rory C. O'Connor, Karen Wetherall, Seonaid Cleare, Sarah Eschle, Julie Drummond, Eamonn Ferguson, Daryl B. O’Connor and Ronan E. O’Carroll

\section{Background}

There are few prevalence studies of suicide attempts and nonsuicidal self-harm (NSSH).

\section{Aims \\ We aimed to estimate the prevalence of thoughts of NSSH, sui- cidal thoughts, NSSH and suicide attempts among 18- to 34-year- olds in Scotland.}

\section{Method}

We interviewed a representative sample of young adults from across Scotland.

\section{Results}

We interviewed 3508 young people; 11.3 and $16.2 \%$ reported a lifetime history of suicide attempts and NSSH, respectively. The first episode of NSSH tended to precede the first suicide attempt by about 2 years. Age at onset of NSSH and suicide attempt was younger in females. Earlier age at onset was associated with more frequent NSSH/suicide attempts. Women are significantly more likely to report NSSH and suicide attempts compared with men.

\section{Conclusions}

One in nine young people has attempted suicide and one in six has engaged in NSSH. Clinicians should be vigilant, as suicide attempts and NSSH are relatively common.

\section{Declaration of interest}

None.

\section{Copyright and usage}

(c) The Royal College of Psychiatrists 2018. This is an Open Access article, distributed under the terms of the Creative Commons Attribution-NonCommercial-NoDerivatives licence (http://creativecommons.org/licenses/by-nc-nd/4.0/), which permits noncommercial re-use, distribution, and reproduction in any medium, provided the original work is unaltered and is properly cited. The written permission of Cambridge University Press must be obtained for commercial re-use or in order to create a derivative work.
Suicide attempts and self-harm are major public health concerns associated with death by suicide. ${ }^{1-5}$ Despite the increased focus on these phenomena, there is still a lack of consensus about how best to conceptualise them. Some argue that self-harm with suicide intent (i.e. a suicide attempt) is distinct from self-harm without suicidal intent (i.e. non-suicidal self-injury, NSSI or nonsuicidal self-harm, NSSH), whereas others argue that the motives underpinning self-harm are multiple and fluid, and others still view them as being on a continuum. ${ }^{2,6-11}$ In this study, we aimed to investigate the prevalence of suicide attempts and NSSH separately and together.

\section{Prevalence rates}

Although the rates of suicide are recorded internationally, ${ }^{12-15}$ nationally representative studies of the prevalence of suicide attempts and NSSH remain scarce. Among adolescents in the USA, the prevalence of suicidal ideation and suicide attempts is estimated to be 12.1 and $4.1 \%$, respectively. ${ }^{16}$ Data from the World Mental Health Surveys across 17 countries suggest the cross-national prevalence of suicidal ideation is $9.2 \%$ and suicide attempts to be $2.7 \% .{ }^{17}$ The European Study of the Epidemiology of Mental Disorders reported the adult lifetime prevalence of suicidal ideation and suicide attempts to be 7.8 and $1.3 \%$, respectively. ${ }^{18}$ In Germany, the lifetime prevalence of NSSI was found to be $3.1 \%$ in a nationally representative sample. ${ }^{19}$ In England, the most recent Adult Psychiatric Morbidity Survey (APMS) found that, across their lifetimes, $20.6 \%$ of respondents had thought about taking their own life, $6.7 \%$ had made a suicide attempt and $7.3 \%$ had engaged in selfharm without suicidal intent. ${ }^{20,21}$ The APMS is one of the only nationally representative large-scale studies to report the prevalence of NSSH as well as suicide attempts (see also Mars et al. ${ }^{8}$ ).

For the most part, large-scale research has focused on school-based studies of adolescent self-harm ${ }^{22-24}$ and monitoring or register-based/ linkage studies of hospital-treated self-harm. ${ }^{25-29}$ Although both types of studies are important, the adolescent findings cannot be generalised to older age groups and the hospital-linkage studies tell us little about suicide attempts and NSSH in the community. Indeed, given that the majority of people who think about or attempt suicide do not receive treatment, ${ }^{30}$ the generalisability of hospital-based studies is limited. To address these evidence gaps, we conducted the Scottish Wellbeing Study, a nationally representative interview-based survey of young adults aged 18-34 years. We targeted the 18- to 34-year-old age group because although suicide attempts and NSSH seem to be common among young adults, ${ }^{17,31}$ we know relatively little about their prevalence in this age group.

\section{Current study}

This is the first nationally representative population-based prevalence study of suicide attempts and NSSH in young adults ever conducted in the UK. As Scotland has a higher suicide rate than England ${ }^{32}$ but both have similar rates of adolescent self-harm, ${ }^{33,34}$ it is important to establish whether the rates of suicide attempts and NSSH diverge in young adulthood. Given that some individuals engage in both behaviours, we also recorded the prevalence of the cooccurrence of suicide attempts and NSSH. In summary, this study aimed to estimate the prevalence of thoughts of NSSH, suicidal thoughts, NSSH and suicide attempts among 18- to 34-year-olds in Scotland.

\section{Method}

\section{Study design, setting and participant recruitment}

This is a cross-sectional study. Participant recruitment was conducted by Ipsos MORI, a social research organisation. We recruited a representative sample of young people aged 18-34 years from across Scotland to the Scottish Wellbeing Study. We employed a 
quota sampling methodology, with quotas based on age (three quota groups), gender and working status. Full details of the sampling design are provided in Appendix 1. It is now argued that a quota sampling design results in a sample with comparable quality to that achieved with a probability sample. ${ }^{35}$ After providing written consent, participants completed a 1 hour-long interview, carried out face-to-face in their homes, using computer-assisted personal interviewing and including a computer-assisted self-interviewing module (the questions about suicide attempts and NSSH were completed confidentially on the computer). The participants completed other psychological and social measures; however, only the prevalence of NSSH and suicide attempts information is reported here. All interviewers were trained in the administration of the measures. Ethical approval was obtained from the Department of Psychology Ethics Committee at the University of Stirling and the US Department of Defense, Human Research Protections Office. Participants received $£ 25$ in compensation for taking part. All participants were given a list of support organisations at the end of the interview.

\section{Measures}

\section{Suicide attempts and NSSH}

Suicide attempts and NSSH were assessed via the following questions, taken from the APMS, respectively ${ }^{20}$ : 'Have you ever made an attempt to take your life, by taking an overdose of tablets or in some other way?' and 'Have you ever deliberately harmed yourself in any way but not with the intention of killing yourself? (i.e. selfharm)'. The questions about self-injurious thoughts were adapted from the APMS and the Child and Adolescent Self-harm in Europe study. ${ }^{22}$ Presence of suicidal thoughts was determined as follows: 'Have you ever seriously thought of taking your life, but not actually attempted to do so?' and respondents completed the following NSSH thoughts question: 'Have you ever seriously thought about trying to deliberately harm yourself but not with the intention of killing yourself but not actually done so?'. If respondents answered yes to either suicide attempts or NSSH, timing of last episode, frequency and age at first onset were asked.

We also report the demographic characteristics (gender, age, marital status, economic activity, ethnicity and accommodation) of the sample here.

\section{Statistical analysis}

Logistic regression analyses, Mann-Whitney $\mathrm{U}$, correlations and chi-square analyses were used to investigate the association between prevalence and characteristics of suicide attempts and NSSH and demographic factors, as appropriate. We also present prevalence ratios to highlight demographic differences. Although it has been argued that error estimates (confidence intervals) cannot be used in quota sampling (because it does not adhere to classical sampling theory), other modelling-based approaches have found that sampling errors are essentially the same as via the classical approach and are reported herein. ${ }^{35,36}$

\section{Weighting}

The data were weighted to ensure that the achieved sample on the quota variables was in line with the population in the sample frame by random iterative method weighting. Overall, as the quotas were almost always met (30- to 34-year-olds, full-time students and full-time workers were slightly underrepresented in the unweighted profile compared with the target profile) the effect of the weights was small, with the weights ranging from 0.81 to 1.30 (therefore the weights would only increase the standard errors of estimates by $1 \%$, see Appendix 1). All analyses were conducted with the weights on.

\section{Missing data}

As the data were collected via interview, most of the missing data were limited to participants declining to answer a question by selecting 'would rather not say'. There were very few respondents with missing data on the lifetime NSSH $(n=39,1.1 \%)$ or suicide attempts $(n=43,1.2 \%)$ variables. In a small number of cases $(n=5)$ where a respondent indicated history of NSSH or suicide attempts but had missing data on the other variable, this was included as NSSH only or suicide attempt only (for the completed variable). Obviously, there is the possibility that these people had engaged in both behaviours, but we do not know for certain.

\section{Results}

\section{Sample and participant characteristics}

A total of 3508 young people were interviewed between 25 March 2013 and 12 December 2013. Over half (50.6\%) of the respondents were male and $37.0 \%$ were aged $18-23$ years, with 35.9 and $27.1 \%$ aged 24-29 and 30-34 years, respectively (see Table 1). The majority of the sample was White (93.8\%) and $83 \%$ of participants were not married. Just over half were in full-time employment, one in five was (19.1\%) in full-time education and $10 \%$ were unemployed. A total of $49.5 \%$ of participants lived in rental accommodation, with the majority of the remainder either owning their own home $(24.1 \%)$ or living with parents/relatives (23.3\%).

\section{Prevalence of suicidal thoughts, suicide attempts, self- harm thoughts and self-harm}

Overall, 11.3 and $16.2 \%$ of the total sample reported a lifetime history of suicide attempts and NSSH, respectively (see Table 2). More than 20\% reported lifetime suicidal thoughts, 2.4\% reported that they last thought about suicide in the past week and $10.4 \%$ reported they last thought about suicide in the past 12 months. Further, 16\% reported thoughts of NSSH at some stage in their lives, $1.7 \%$ reported that they last thought about NSSH in the past week and $7.3 \%$ reported they last thought about NSSH in the past 12 months. Very few respondents $(0.3 \%)$ reported that they had last attempted suicide in the past week and $2.7 \%$ reported their last attempt in the past 12 months. Approximately $1 \%(1.1 \%)$ of respondents reported that their last NSSH episode was in the past week with $4.8 \%$ reported their most recent episode within the past 12 months (all of the past 12 month rates include the past week rates).

Approximately $10 \%$ of respondents $(9.8 \% ; 95 \% \mathrm{CI}=8.9-10.8 \%)$ engaged in NSSH only, $4.8 \%(95 \% \mathrm{CI}=4.2-5.6 \%)$ had attempted suicide only and $6.5 \%(95 \% \mathrm{CI}=5.7-7.3 \%)$ had attempted suicide and engaged in NSSH (the 'both' group). Of those who had attempted suicide, $57.3 \%$ had also engaged in NSSH and of those who reported NSSH, 39.7\% also had a suicide attempt history.

Approximately $60 \%(60.8 \%)$ of those who have attempted suicide reported doing so more than once (range: 1-75 times, mean: 3.52 (s.d. =7.23), median: 2) and $80 \%$ of those with an NSSH history had harmed themselves more than once (range: 199 times, mean: 9.39 (s.d. = 16.23), median: 4). The age at onset of the first episode of NSSH (mean: 16.05 (s.d. =4.12), range: 5-32 years, median: 15 years) was younger than that for age at first suicide attempt (mean: 17.81 (s.d. $=4.99$ ), range: 6-34 years, median: 17 years). Age at onset for first NSSH episode was significantly older in men (median: 16 years, mean: 16.56 (s.d. $=4.23$ ), range: 6-29 years) compared with women (median: 15 years, 


\begin{tabular}{|c|c|c|c|c|c|c|c|c|}
\hline \multirow[t]{3}{*}{ Characteristic } & \multicolumn{8}{|c|}{ Age group, years } \\
\hline & \multicolumn{2}{|c|}{$18-23, n(\%)$} & \multicolumn{2}{|c|}{$24-29, n(\%)$} & \multicolumn{2}{|c|}{$30-34, n(\%)$} & \multicolumn{2}{|c|}{ Total, $N(\%)$} \\
\hline & Not weighted & Weighted & Not weighted & Weighted & Not weighted & Weighted & Not weighted & Weighted \\
\hline \multicolumn{9}{|l|}{ Gender } \\
\hline Male & $719(52.4)$ & $690(53.2)$ & $620(49.2)$ & $639(50.7)$ & $401(45.8)$ & $446(47.0)$ & $1740(49.6)$ & $1775(50.6)$ \\
\hline Female & 654 (47.6) & $608(46.8)$ & $639(50.8)$ & $621(49.3)$ & 475 (54.2) & $504(53.0)$ & $1768(50.4)$ & $1733(49.4)$ \\
\hline \multicolumn{9}{|l|}{ Ethnicity } \\
\hline White & $1307(95.2)$ & $1234(95.0)$ & $1175(93.8)$ & $1174(93.2)$ & $816(93.2)$ & $884(93.0)$ & $3298(94.8)$ & $3291(93.8)$ \\
\hline South Asian & $20(1.5)$ & $19(1.5)$ & $28(2.2)$ & $28(2.2)$ & $23(2.6)$ & $26(2.7)$ & $71(2.0)$ & $73(2.1)$ \\
\hline Chinese/other Asian & $11(0.8)$ & $11(0.8)$ & $19(1.5)$ & $20(1.6)$ & $6(0.7)$ & $7(0.7)$ & $36(1.0)$ & $37(1.1)$ \\
\hline Black & $10(0.7)$ & $10(0.7)$ & $19(1.5)$ & $19(1.5)$ & $10(1.1)$ & $11(1.2)$ & $39(1.1)$ & $40(1.1)$ \\
\hline Other & $11(0.8)$ & $11(0.8)$ & $10(0.8)$ & $10(0.8)$ & $13(1.5)$ & $14(1.5)$ & $34(1.0)$ & $35(1.0)$ \\
\hline \multicolumn{9}{|l|}{ Marital status } \\
\hline Married/ civil partnership & $34(2.5)$ & $30(2.3)$ & $227(18.0)$ & $227(18.0)$ & $309(35.3)$ & $337(35.4)$ & $570(16.3)$ & $594(17.0)$ \\
\hline Not married ${ }^{\mathrm{a}}$ & 1339 (97.5) & $1268(97.7)$ & $1031(82.0)$ & $1032(82.0)$ & $567(64.7)$ & $614(64.6)$ & 2937 (83.7) & $2913(83.0)$ \\
\hline \multicolumn{9}{|l|}{ Economic activity } \\
\hline Full-time employed & 466 (33.9) & 439 (33.8) & $742(58.9)$ & $770(61.1)$ & $531(60.6)$ & $602(63.3)$ & $1739(49.6)$ & $1810(51.6)$ \\
\hline Full-time education & 470 (34.3) & $503(38.7)$ & $100(7.9)$ & $117(9.3)$ & $39(4.5)$ & $50(5.3)$ & 609 (17.4) & $670(19.1)$ \\
\hline Other & $437(31.8)$ & 356 (27.5) & 417 (33.2) & $372(29.6)$ & $306(34.9)$ & $299(31.4)$ & $1160(33.0)$ & $1028(29.3)$ \\
\hline Part-time employed & $161(11.7)$ & $131(10.1)$ & $138(11.0)$ & $123(9.8)$ & $101(11.5)$ & $98(10.4)$ & $400(11.4)$ & $352(10.0)$ \\
\hline Unemployed & 191 (13.9) & $156(12.1)$ & $134(10.6)$ & $120(9.6)$ & $80(9.1)$ & $79(8.3)$ & 405 (11.5) & $356(10.1)$ \\
\hline Sick/disabled & $14(1.0)$ & $11(0.9)$ & $23(1.8)$ & $21(1.6)$ & $41(4.7)$ & $40(4.2)$ & $78(2.2)$ & $72(2.1)$ \\
\hline Homemaker & $61(4.4)$ & $49(3.8)$ & $115(9.1)$ & $102(8.1)$ & $76(8.7)$ & $74(7.8)$ & $252(7.2)$ & $225(6.4)$ \\
\hline Other & $10(0.7)$ & $8(0.6)$ & $7(0.6)$ & $6(0.5)$ & $8(0.9)$ & $8(0.8)$ & $25(0.7)$ & $22(0.6)$ \\
\hline \multicolumn{9}{|l|}{ Accommodation } \\
\hline Owns home & $159(11.6)$ & $152(11.7)$ & 307 (24.4) & $311(24.7)$ & $348(39.7)$ & $383(40.3)$ & 814 (23.2) & $845(24.1)$ \\
\hline Rent - social housing & $220(16.0)$ & $195(15.0)$ & $338(26.8)$ & $327(26.0)$ & $255(29.1)$ & $269(28.3)$ & $813(23.2)$ & $791(22.6)$ \\
\hline Private rent & $327(23.8)$ & $316(24.4)$ & 391 (31.1) & 395 (31.4) & 213 (24.3) & $233(24.6)$ & $931(26.6)$ & 945 (26.9) \\
\hline Lives with parents/relatives & $608(44.3)$ & $577(44.5)$ & $188(14.9)$ & $191(15.1)$ & $47(5.4)$ & $51(5.4)$ & $843(24.1)$ & $819(23.3)$ \\
\hline Other & $58(4.2)$ & $57(4.4)$ & $32(2.5)$ & $33(2.6)$ & $12(1.4)$ & $13(1.4)$ & $102(2.9)$ & $103(2.9)$ \\
\hline
\end{tabular}

mean: 15.77 (s.d. $=4.04$ ), range: $5-32$ years; $Z=-2.64, P=0.008$ ). A similar gender $\times$ age association for first suicide attempt was also evident (median: 18 years, mean: 18.29 (s.d. $=5.00$ ), range: 6-34 years for men $v$. median: 16 years, mean: $17.5($ s.d. $=4.97)$, range: 6-33 years for women; $Z=-2.62, P=0.009$ ), with women reporting first episodes of NSSH younger than men. For both NSSH and suicide attempts, earlier age at onset was correlated with more frequent episodes of NSSH (Spearman's rho $=-0.20, P<0.001$ ) and suicide attempts (Spearman's rho $=-0.30, P<0.001$ ) in the whole sample and for men (Spearman's rho $=-0.18, P=0.018$ for NSSH and Spearman's rho $=-0.23, P=0.006$ for suicide attempts) and women separately (Spearman's rho $=-0.21, P<$ 0.001 for NSSH and Spearman's rho $=-0.33, P<0.001$ for suicide attempts).

As detailed in Table 2, lifetime suicide attempts were reported more often by women $(13.8 \%)$ than men $(8.8 \%$; prevalence ratio, 1.02; odds ratio, $1.67 ; 95 \% \mathrm{CI}=1.35-2.07, P<0.0001)$ and NSSH was also more commonly reported by women $(20.9 \%)$ than men (11.6\%; prevalence ratio, 1.80 ; odds ratio, 2.02 ; $95 \% \mathrm{CI}=1.68-$ $2.43, P<0.0001)$. Similar numbers of men $(22.6 \%)$ and women (23.0\%; prevalence ratio, 1.02 ; odds ratio, 1.02 ; $95 \% \mathrm{CI}=0.87$ $1.20, P=0.80)$ reported suicidal thoughts across their lifetime whereas thoughts of NSSH were more common in women (19.2v. $12.3 \%$ for men; prevalence ratio, 1.56 ; odds ratio, $1.69 ; 95 \% \mathrm{CI}=$ $1.40-2.04, P<0.0001)$.

Prevalence of lifetime history of suicide attempts was significantly lower among 18 - to 23 -year-olds, being $9 \%$ compared with $12.2 \%$ in 24 - to 29 -year-olds (prevalence ratio, 1.36; odds ratio, $1.40 ; 95 \% \mathrm{CI}=1.08-1.80, P=0.010$ ), with 30 - to 34 -year-olds reporting similar rates of suicide attempts to the 24 - to 29 -yearolds, at $13 \%$ (prevalence ratio, 1.07 ; odds ratio, 1.08 ; $95 \% \mathrm{CI}=$ $0.84-1.39, P=0.564)$. Although the lifetime prevalence of selfharm is similar in $18-23(18.6 \%)$ and 24 - to 29 -year-olds (17.1\%; prevalence ratio, 0.92 ; odds ratio, $0.90 ; 95 \% \mathrm{CI}=0.74-1.10$, $P=0.315)$, it is markedly lower among 30 - to 34 -year-olds compared with 24 - to 29 -year-olds ( $11.7 \%$; prevalence ratio, 0.68 ; odds ratio, $0.64 ; 95 \%$ CI, $0.50-0.82, P<0.0001)$. The age distribution for female NSSH and suicide attempts mirrors that for the sample as a whole, whereas male NSSH peaks in the 24- to 29-year-old age group.

The sociodemographic characteristics as a function of lifetime NSSH and suicide attempt histories are summarised in Table 3. Not being married was associated with increased likelihood of NSSH (17.4 v. 10.5\% for not married and married, respectively; prevalence ratio, 1.66 ; odds ratio, $1.79 ; 95 \% \mathrm{CI}=1.35-2.37$, $P<0.0001)$ but not of suicide attempts $(11.7 v .9 .2 \%$ for not married and married, respectively; prevalence ratio, 1.27; odds ratio, $1.31 ; 95 \% \mathrm{CI}=0.97-1.78, P=0.077$; see Table 3 ). The prevalence of NSSH and suicide attempts was significantly higher among those classified as unemployed (20.3\%; prevalence ratio, 1.53; odds ratio, $1.67 ; 95 \% \mathrm{CI}=1.25-2.23, P<0.0001$ and $20.6 \%$; prevalence ratio, 2.24; odds ratio, $2.53 ; 95 \% \mathrm{CI}=1.88-3.40$, $P<0.0001$ for NSSH and suicide attempts, respectively) and economically inactive (21.2\%; prevalence ratio, 1.59 ; odds ratio, 1.76 ; $95 \% \mathrm{CI}=1.44-2.15, P<0.0001$ for NSSH and $12.3 \%$; prevalence ratio, 1.34 ; odds ratio, $1.38 ; 95 \% \mathrm{CI}=1.09-1.76, P=0.008$ for suicide attempts) compared with those who were employed (13.3\% for NSSH and $9.2 \%$ for suicide attempts). Ethnicity was not associated with prevalence of NSSH or suicide attempts. Compared with those who own their own home (10.3\% reported NSSH), those living in rental (19.1\% reported NSSH; prevalence ratio, 1.85 ; odds ratio, 2.06 ; $95 \% \mathrm{CI}=1.60-2.65, P<0.0001$ ) or other accommodation ( $16.3 \%$ reported NSSH; prevalence ratio, 1.58; odds ratio, $1.70 ; 95 \% \mathrm{CI}=1.28-2.25, P<0.0001)$ were more likely to report NSSH. Those in rental accommodation were also significantly more likely to report a suicide attempt 
18-23 years

24-29 years

30-34 years

All age groups

\section{Men}

Suicidal thoughts

suicide attempts

Non-suicidal self-harm thoughts

Non-suicidal self-harm

Women

Suicidal thoughts

Suicide attempts

Non-suicidal self-harm

\section{Prevalence ratios $^{\mathrm{a}}$}

Suicidal thoughts

suicide attempts

Non-suicidal self-harm thoughts

Non-suicidal self-harm

All adults

Suicidal thoughts

Non-suicidal self-harm thoughts

Non-suicidal self-harm

Bases $^{\text {b }}$

Men

Women

$$
\begin{aligned}
& 1.27 \\
& 3.27 \\
& 2.30 \\
& 3.28
\end{aligned}
$$

$9.9(7.9-12.4)$

$1.5(0.8-2.7)$

$5.4(4.0-7.4)$

$3.2(2.1-4.8)$

$12.6(10.2-15.6)$

$4.9(3.4-6.9)$

$12.4(10.0-15.3)$

$10.5(8.3-13.2)$

$11.2(9.6-13.1)$

$3.1(2.3-4.2)$

$8.7(7.2-10.3)$

$6.6(5.3-8.1)$

719

654
$25.2(22.0-28.8)$

$10.3(8.2-12.9)$

$14.1(11.6-17.0)$

$14.5(12.0-17.5)$

$24.1(20.9-27.7)$

$14.2(11.6-17.2)$

$18.2(15.3-21.4)$

$19.7(16.8-23.0)$

0.96

1.38
1.29

1.36

24.7 (22.3-27.2)

$12.2(10.5-14.2)$

$16.1(14.2-18.2)$

$17.1(15.1-19.3)$

620

259

$$
\begin{aligned}
& 0.93 \\
& 0.90 \\
& 1.15 \\
& 1.21
\end{aligned}
$$

$11.6(9.3-14.4)$ $2.9(1.8-4.5)$ $6.7(5.0-8.9)$ $4.3(3.0-6.1)$

$10.8(8.5-13.5)$ $2.6(1.6-4.2)$ $7.7(5.9-10.1)$ $5.2(3.7-7.2)$

$11.3(9.6-13.2)$ $2.7(2.0-3.8)$

$7.2(5.9-8.8)$

$4.7(3.7-6.0)$

620

639

$$
\begin{aligned}
& 0.98 \\
& 1.50 \\
& 1.59 \\
& 1.69
\end{aligned}
$$

$22.5(18.9-26.7)$

$0.3(7.8-13.5)$

$10.5(8.0-13.8)$

$8.6(6.4-11.6)$

$15.4(12.5-18.9)$

$14.5(11.7-17.9)$

$22.2(19.6-25.0)$

$13.0(11.0-15.3)$

$13.9(11.8-16.3)$

$11.7(9.8-14.0)$

401
475

475
876

a A prevalence ratio $>1$ means that women are more likely to report the thought/behaviour, with a prevalence ratio $<1$ indicating that men are more likely to report the thought/behaviour and a prevalence ratio $=1$ means the rates for reporting the thought/behaviour are the same for men and women.
b Numbers are unweighted, percentages are weighted.

$\begin{array}{lcc}8.7(6.4-11.8) & 22.6(20.7-24.6) & 10.2(8.9-11.7) \\ 2.5(1.4-4.4) & 8.8(7.5-10.2) & 2.2(1.6-3.0) \\ 5.0(3.3-7.5) & 12.3(10.7-13.7) & 5.8(4.8-7.0) \\ 2.5(1.4-4.4) & 11.6(10.1-13.1) & 3.4(2.7-4.4) \\ & & \\ 7.9(5.8-10.6) & 23.0(21.0-25.0) & 10.6(9.3-12.2) \\ 2.0(1.1-3.7) & 13.8(12.3-15.6) & 3.2(2.5-4.3) \\ 6.3(4.4-8.7) & 19.2(17.4-21.1) & 8.9(7.7-10.4) \\ 2.4(1.4-4.2) & 20.9(19.1-22.9) & 6.2(5.1-7.4) \\ 0.91 & & \\ 0.80 & 1.02 & 1.04 \\ 1.26 & 1.57 & 1.46 \\ 0.96 & 1.56 & 1.53 \\ & 1.80 & 1.82 \\ 8.3(6.7-10.3) & 22.8(21.4-24.2) & 10.4(9.4-11.5) \\ 2.2(1.5-3.4) & 11.3(10.3-12.4) & 2.7(2.2-3.3) \\ 5.6(4.3-7.0) & 15.7(14.5-17.0) & 7.3(6.5-8.2) \\ 2.4(1.6-3.5) & 16.2(15.0-17.5) & 4.8(4.2-5.6) \\ 401 & & \\ 475 & 1740 & 1740 \\ 876 & 1768 & 3508\end{array}$


Table 3 Descriptive statistics for sociodemographic characteristics and lifetime non-suicidal self-harm and suicide attempt history

\begin{tabular}{|c|c|c|c|c|}
\hline Sociodemographic characteristic & $\begin{array}{l}\text { No self-harm (control), } \\
\begin{array}{c}n=2731(78.9 \%), \\
\%(95 \% \mathrm{Cl})\end{array}\end{array}$ & $\begin{array}{l}\text { NSSH only, } \\
n=339(9.8 \%) \\
\%(95 \% \mathrm{Cl})\end{array}$ & $\begin{array}{l}\text { Suicide attempts only, } \\
\qquad \begin{array}{c}n=167(4.8 \%), \\
\%(95 \% \mathrm{Cl})\end{array}\end{array}$ & $\begin{array}{l}\text { NSSH and suicide attempts, } \\
\qquad \begin{array}{c}n=223(6.5 \%), \\
\%(95 \% \mathrm{Cl})\end{array}\end{array}$ \\
\hline Gender (female) & $46.4(44.6-48.3)$ & $60.2(54.9-65.3)$ & $48.6(41.0-56.0)$ & $69.2(63.2-75.2)$ \\
\hline \multicolumn{5}{|l|}{ Age } \\
\hline 18-23 years & $36.5(34.7-38.3)$ & $49.3(44.0-54.6)$ & $26.7(20.8-34.1)$ & $32.1(26.5-38.7)$ \\
\hline 24-29 years & $35.7(34.0-37.6)$ & $36.1(31.1-41.2)$ & $36.0(29.0-43.5)$ & $41.1(35.0-47.8)$ \\
\hline 30-34 years & $27.8(26.1-29.5)$ & $14.6(11.4-18.9)$ & $37.3(30.2-44.7)$ & $26.8(21.5-33.1)$ \\
\hline $\begin{array}{l}\text { Marital status (married/civil partnership } \\
\text { versus not married }{ }^{\text {a }} \text { ) }\end{array}$ & $18.4(17.0-19.9)$ & $9.1(6.5-12.7)$ & $13.7(9.4-19.8)$ & $13.9(10.0-19.1)$ \\
\hline \multicolumn{5}{|l|}{ Economic activity ${ }^{\mathrm{b}}$} \\
\hline Employed & $64.7(62.9-66.5)$ & $52.9(47.5-58.1)$ & $55.0(47.5-62.4)$ & $47.8(41.5-54.5)$ \\
\hline Unemployed & $8.9(7.9-10.0)$ & $10.2(7.5-14.0)$ & $21.5(16.0-28.4)$ & $16.4(12.3-22.0)$ \\
\hline Economically inactive & $26.4(24.8-28.1)$ & $36.9(31.9-42.1)$ & $23.5(17.6-30.3)$ & $35.8(29.9-42.4)$ \\
\hline $\begin{array}{l}\text { Ethnic group }{ }^{\mathrm{C}} \text { (White versus Black and } \\
\text { minority ethnic) }\end{array}$ & $93.8(92.8-94.7)$ & $92.5(89.4-95.0)$ & $94.9(90.1-97.1)$ & $95.2(92.0-97.6)$ \\
\hline \multicolumn{5}{|l|}{ Accommodation ${ }^{d}$} \\
\hline Owns own home & $26.9(25.3-28.6)$ & $17.8(14.0-22.1)$ & $12.7(8.4-18.5)$ & $11.9(8.5-17.1)$ \\
\hline Rent & $46.1(44.1-47.9)$ & $52.5(47.1-57.8)$ & $74.6(67.1-80.3)$ & $66.8(60.4-72.7)$ \\
\hline Other & $27.0(25.3-28.7)$ & $29.7(25.2-34.9)$ & $12.7(8.4-18.5)$ & $21.3(16.6-27.4)$ \\
\hline \multicolumn{5}{|c|}{$\begin{array}{l}\text { Note. Number of respondents with missing data was } 0 \text { for gender, } 0 \text { for age, } 1 \text { for marital status, } 0 \text { for economic activity, } 2 \text { for ethnic group, } 5 \text { for accommodation. } \\
\text { NHSS, non-suicidal self-harm. } \\
\text { a Not married includes never married, separated, divorced and widowed. } \\
\text { b Economic activity has been reduced to three categories based upon the Adult Psychiatric Morbidity survey data-set: employed (economically active people), unemployed (those out of } \\
\text { work but are available to start work) and economically inactive (including students, those looking after the home, long-term sick, disabled or retired). } \\
\text { c Ethnicity was collapsed into two ethnic groups (White versus Black and minority ethnic). } \\
\text { d Accommodation has been reduced to three categories: owns own home, rent (private rental and social housing) and other (lives with parents/relatives, other). }\end{array}$} \\
\hline
\end{tabular}

compared with those who owned their own home (16.0 v. 5.7\%; prevalence ratio, 2.81; odds ratio, 3.17; 95\% CI $=2.30-4.37, P<$ 0.0001).

\section{Discussion}

Suicide attempts and NSSH are major public health concerns that affect large numbers of young people. Eleven per cent of young people aged 18-34 years report having attempted suicide and $16 \%$ report having self-harmed without suicidal intent at some stage in their lives. Women are 1.6 times more likely to report a suicide attempt than men and 1.8 times more women reported NSSH compared with men. Almost a quarter (22.8\%) of young people also reported lifetime suicidal thoughts. For NSSH and suicide attempts, age at first episode tends to be during adolescence, with NSSH (mean age: 16.05 years, s.d. $=4.12$ ) occurring, on average, 2 years earlier than suicide attempts $(17.81$ years, s.d. $=4.99)$. It is concerning that the majority of respondents who engaged in NSSH (80\%) or suicide attempts (60\%) did so more than once. Earlier age at NSSH or suicide attempt onset was associated with more frequent lifetime NSSH and suicide attempts and age at onset was younger in females compared with males. Moreover, $6.5 \%$ of the sample had engaged in both NSSH and attempted suicide at least once. Approximately $3 \%$ $(2.7 \%)$ and $5 \%(4.8 \%)$ of young people have attempted suicide and engaged in NSSH, respectively, in the past 12 months. Among the total sample, rates of NSSH were highest among the 18- to 23-year-old age group, whereas suicide attempt rates were most common among the 30 - to 34 -year-olds. The same pattern was evident in women, whereas NSSH was most common among 24 - to 29-year-old men. One in five young adults who were classified as unemployed reported an NSSH and a suicide attempt history, and another 20 and $12 \%$ of those who were economically inactive reported NSSH and suicide attempts, respectively.

History of suicide attempts and NSSH was ascertained in the same way in our study as in the English APMS. ${ }^{20}$ So, although the raw data from the latter are not yet available, we used the published
APMS summary tables to compare the rates of suicide attempts and NSSH in both countries. In the youngest age groups, the rates were similar in Scotland and England (the prevalence rates of lifetime suicide attempts in the Scottish Wellbeing Study (18- to 23-yearolds) and in the APMS (16- to 24-year-olds) were both 9\%; rates of NSSH were 18.6 and $17.5 \%$ for Scotland and England, respectively). However, lifetime rates of suicide attempts and NSSH were higher in the Scottish sample among the older ages. Whereas the rates of suicide attempts and NSSH among 24- to 34-year-olds (we collapsed the 24- to 29-year-old and 30- to 34-year-old age groups) in this study were 12.6 and $14.8 \%$, respectively, the comparable rates in the APMS were 8.5 and $12.1 \%$ for 25 - to 34 -year-olds in England. Given that the national suicide rates are higher in Scotland compared with England, ${ }^{37}$ these suicide attempt data may suggest that risk begins to diverge in the mid-twenties. Future research is required to determine why the rates begin to diverge in this age group; are there structural factors (which increase health inequalities, for example) in Scotland compared with England that may explain this age divergence? Caution is urged though, as the APMS is an adult lifespan study whereas the Scottish Wellbeing Study focused on young people specifically. Moreover, the APMS included young people aged 16 years and over whereas the Scottish Wellbeing Study was restricted to those who were at least 18 years old. It would be informative, therefore, to replicate the Scottish Wellbeing Study in England to yield directly comparable prevalence figures for young adults.

This study has many strengths (including large representative sample, being interview-based and confidential completion), however, it is important to recognise that suicidal history was assessed via self-report (albeit via computer) and, therefore, the responses were subject to standard reporting biases. Consistent with other large-scale surveys, ${ }^{20}$ it was not optimal that suicide attempts and NSSH were assessed via single questions, although these specific questions have been widely used. Also, given the evidence that some people inconsistently report their self-harm/suicidal history, reliance on self-report may lead to the underreporting of suicide attempts and NSSH, therefore combining data from multiple sources may more accurately reflect the actual prevalence of suicide 
attempts and $\mathrm{NSSH}^{38}$ The use of quota sampling also requires comment. Historically, quota sampling may have yielded a biased sample (as non-responding individuals are ignored and the interviewer is selecting people or households), however, it is now argued that a rigorously designed quota sample (as conducted here) is as good as a probability sample. ${ }^{35,39,40}$ This is the baseline wave of a longitudinal study, therefore, the incidence rates of suicide attempts and NSSH over time will be reported in due course, as well as the associations with psychological risk and protective factors.

The findings are stark and clinically important as they highlight the scale of suicide attempts and NSSH among 18- to 34-year-olds and their demographic profile. Given that the vast majority of respondents who reported NSSH and suicide attempt did so more than once, clinicians should assess risk of repetition if a young person presents with an index suicide attempt or NSSH episode. Moreover, earlier onset of NSSH/suicide attempt is clinically significant in particular given its association with more frequent NSSH/ suicide attempts. In such cases, clinicians should assess the factors (e.g. impulsivity, exposure, suicidal imagery, fearlessness about death, access to means) known to increase the likelihood that thoughts of suicide and self-harm are acted upon. ${ }^{41-45}$ From a public health perspective, the unemployment and economic inactivity findings are noteworthy. However, as these data are from a retrospective study, the direction of the relationship between unemployment and economic inactivity and NSSH/suicide attempts is unclear. Nonetheless, these findings are consistent with the extant suicide research literature on health and social inequality and highlight the importance of supporting those who are unemployed and economically inactive. ${ }^{46}$

Psychiatrists, psychologists and others involved in the care of young people should be vigilant. Given the prevalence of suicide attempts and NSSH in this age group, they should routinely enquire about history of self-injurious behaviour, especially as past behaviour is such a strong predictor of suicide. ${ }^{3}$ In conclusion, both NSSH and suicide attempts are common among young people in Scotland, with at least one in nine reporting lifetime prevalence of suicide attempts and one in six reporting NSSH, and 6.5\% reporting a history of both behaviours.

Rory C. O'Connor, PhD, Karen Wetherall, MSC, Seonaid Cleare, BSC, Sarah Eschle MA, Julie Drummond, MSc, Suicidal Behaviour Research Laboratory, Institute of Health \& Wellbeing, University of Glasgow, UK; Eamonn Ferguson, PhD, School of Psychology, University of Nottingham, UK; Daryl B. O'Connor, PhD, School of Psychology, University of Leeds, UK; Ronan E. O'Carroll, PhD, Division of Psychology, School of Natural Sciences, University of Stirling, UK

Correspondence: Rory C. O'Connor, Suicidal Behaviour Research Laboratory, Institute of Health \& Wellbeing, University of Glasgow, Glasgow, G12 0XH. Email: rory.oconnor@ glasgow.ac.uk

First received 6 Nov 2017, final revision 14 Jan 2018, accepted 22 Feb 2018

\section{Funding}

This study was funded by a grant from US Department of Defense (W81XWH-12-1-0007). The funder had no role in study design, data collection, data analysis, data interpretation or writing of this article. The corresponding author had full access to all the data in the study and had final responsibility for the decision to submit for publication. Opinions, interpretations, conclusions and recommendations are those of the authors and are not necessarily endorsed by the funder.

\section{Acknowledgements}

Many thanks to Ipsos MORI (in particular Steven Trainor, Sara Davidson and Chris Martin), whose staff recruited the participants and conducted the interviews.

\section{Supplementary material}

Supplementary material is available online at https://doi.org/10.1192/bjo.2018.14.

\section{References}

1 Turecki G, Brent DA. Suicide and suicidal behaviour. Lancet 2016; 387(10024): 1227-39.

2 Hawton K, Saunders KE, O'Connor RC. Self-harm and suicide in adolescents. Lancet 2012; 379(9834): 2373-82.

3 O'Connor RC, Nock MK. The psychology of suicidal behaviour. Lancet Psychiatry 2014; 1(1): 73-85.

4 Cooper J, Kapur N, Webb R, Lawlor M, Guthrie E, Mackway-Jones K, et al. Suicide after deliberate self-harm: a 4-year cohort study. Am J Psychiatry 2005; 162(2): 297-303.

5 Rodway C, Tham SG, Ibrahim S, Turnbull P, Windfuhr K, Shaw J, et al. Suicide in children and young people in England: a consecutive case series. Lancet Psychiatry 2016; 3(8): 751-9.

6 Kapur N, Cooper J, O'Connor RC, Hawton K. Non-suicidal self-injury v. attempted suicide: new diagnosis or false dichotomy? Br J Psychiatry 2013; 202(5): 326-8.

7 Butler AM, Malone K. Attempted suicide v. non-suicidal self-injury: behaviour, syndrome or diagnosis? Br J Psychiatry 2013; 202(5): 324-5.

8 Mars B, Heron J, Crane C, Hawton K, Kidger J, Lewis G, et al. Differences in risk factors for self-harm with and without suicidal intent: findings from the ALSPAC cohort. J Affect Disord 2014; 168: 407-14.

9 Wilkinson P, Kelvin R, Roberts C, Dubicka B, Goodyer I. Clinical and psychosocial predictors of suicide attempts and nonsuicidal self-injury in the Adolescent Depression Antidepressants and Psychotherapy Trial (ADAPT). Am J Psychiatry 2011; 168(5): 495-501.

10 Klonsky ED, May AM, Glenn CR. The relationship between nonsuicidal self-injury and attempted suicide: converging evidence from four samples. I Abnorm Psychol 2013; 122(1): 231-7.

11 Hamza CA, Stewart SL, Willoughby T. Examining the link between nonsuicidal self-injury and suicidal behavior: a review of the literature and an integrated model. Clin Psychol Rev 2012; 32(6): 482-95.

12 World Health Organization. Preventing suicide: a global imperative. World Health Organization, 2014

13 Coope C, Gunnell D, Hollingworth W, Hawton K, Kapur N, Fearn V, et al. Suicide and the 2008 economic recession: who is most at risk? Trends in suicide rates in England and Wales 2001-2011. Soc Sci Med 2014; 117: 76-85.

14 Qin P, Agerbo E, Mortensen PB. Suicide risk in relation to socioeconomic, demographic, psychiatric, and familial factors: a national register-based study of all suicides in Denmark, 1981-1997. Am J Psychiatry 2003; 160(4): 765-72.

15 Varnik P. Suicide in the world. Int J Environ Res Public Health 2012; 9(3): 760-71.

16 Nock MK, Green JG, Hwang I, McLaughlin KA, Sampson NA, Zaslavsky AM, et al. Prevalence, correlates, and treatment of lifetime suicidal behavior among adolescents results from the national comorbidity survey replication adolescent supplement. JAMA Psychiatry 2013; 70(3): 300-10.

17 Nock MK, Borges G, Bromet EJ, Alonso J, Angermeyer M, Beautrais A, et al. Cross-national prevalence and risk factors for suicidal ideation, plans and attempts. Br J Psychiatry 2008; 192(2): 98-105.

18 Bernal M, Haro JM, Bernert S, Brugha T, de Graaf R, Bruffaerts R, et al. Risk factors for suicidality in Europe: results from the ESEMED study. J Affect Disord 2007; 101(1-3): 27-34.

19 Plener PL, Allroggen M, Kapusta ND, Brahler E, Fegert JM, Groschwitz RC. The prevalence of Nonsuicidal Self-Injury (NSSI) in a representative sample of the German population. BMC Psychiatry 2016; 16: 7 .

20 McManus S, Hassiotis A, Jenkins R, Dennis M, Aznar C, Appleby L. Chapter 12: suicidal thoughts, suicide attempts and self-harm. In Mental Health and Wellbeing in England: Adult Psychiatric Morbidity Survey 2014 (eds S McManus, P Bebbington, R Jenkins, T Brugha). NHS Digital, 2016.

21 McManus S, Bebbington $P$, Jenkins $R$, Brugha $T$ (eds). Mental Health and Wellbeing in England: Adult Psychiatric Morbidity Survey 2014. NHS Digital, 2016.

22 Madge N, Hewitt A, Hawton K, de Wilde EJ, Corcoran P, Fekete S, et al. Deliberate self-harm within an international community sample of young people: comparative findings from the Child \& Adolescent Self-harm in Europe (CASE) Study. J Child Psychol Psychiatry 2008; 49(6): 667-77.

23 O'Connor RC, Rasmussen S, Hawton K. Adolescent self-harm: a school-based study in Northern Ireland. J Affect Disord 2014; 159: 46-52.

24 Moran P, Coffey C, Romaniuk H, Olsson C, Borschmann R, Carlin JB, et al. The natural history of self-harm from adolescence to young adulthood: a population-based cohort study. Lancet 2012; 379(9812): 236-43.

25 Perry IJ, Corcoran P, Fitzgerald AP, Keeley HS, Reulbach U, Arensman E. The incidence and repetition of hospital-treated deliberate self harm: findings from the world's first national registry. PLOS One 2012; 7(2): 7. 
26 Olfson M, Wang S, Blanco C. National trends in hospital-treated selfharm events among middle-aged adults. Gen Hosp Psychiatry 2015; 37(6): 613-9.

27 Hatcher S, Sharon C, Collins N. Epidemiology of intentional self-harm presenting to four district health boards in New Zealand over 12 months, and comparison with official data. Aust N Z J Psych 2009; 43(7): 659-65.

28 Owens D, Horrocks J, House A. Fatal and non-fatal repetition of self-harm Systematic review. Br J Psychiatry 2002; 181: 193-9.

29 Hawton K, Haw C, Casey D, Bale L, Brand F, Rutherford D. Self-harm in Oxford, England: epidemiological and clinical trends, 1996-2010. Soc Psychiatry Psychiatr Epidemiol 2015; 50(5): 695-704.

30 Bruffaerts R, Demyttenaere K, Hwang I, Chiu WT, Sampson N, Kessler RC, et al. Treatment of suicidal people around the world. Br J Psychiatry 2011; 199(1): 64-70.

31 Meltzer H, Lader D, Corbin T, Singleton N, Jenkins R, Brugha T. Non-fatal suicidal behaviour among adults aged 16 to 74 in Great Britain. The Office for National Statistics, 2002

32 Armitage CJ. Evidence that a volitional help sheet reduces alcohol consumption among smokers: a pilot randomized controlled trial. Behav Ther 2015; 46(3): 342-9.

33 Hawton K, Rodham K, Evans $\mathrm{E}$, weatherall R. Deliberate self harm in adolescents: self report survey in schools in England. Br Med J 2002; 325(7374): 1207-11.

34 O'Connor RC, Rasmussen S, Miles J, Hawton K. Self-harm in adolescents: self-report survey in schools in Scotland. Br J Psychiatry 2009; 194(1): 68-72.

35 Raab G. Annex: Scottish environmental attitudes and behaviours survey 2008 technical annex on survey design. In Scottish Environmental Attitudes and Behaviours Survey 2008 - Technical Report (eds S Davidson, C Martin, S Treanor). Scottish Government Social Research, 2009.

36 Deville JC. A theory of quota surveys. Surv Methodol 1991; 17: 163-81.
37 Mok PLH, Kapur N, Windfuhr K, Leyland AH, Appleby L, Platt S, et al. Trends in national suicide rates for Scotland and for England \& Wales, 1960-2008. Br J Psychiatry 2012; 200(3): 245-51.

38 Mars B, Cornish R, Heron J, Boyd A, Crane C, Hawton K, et al. Using data linkage to investigate inconsistent reporting of self-harm and questionnaire nonresponse. Arch Suicide Res 2016; 20(2): 113-41.

39 Cumming RG. Is probability sampling always better? A comparison of results from a quota and a probability sample survey. Community Health Stud 1990; 14: $132-7$.

40 Groves RM, Fowler FJ, Couper MP, Lepkowski JM, Singer E, Tourangeau R. Survey Methodology. Wiley, 2009.

41 O'Connor RC, Cleare S, Eschle S, Wetherall K, Kirtley OJ. The integrated motivational-volitional model of suicidal behavior: an update. In The International Handbook of Suicide Prevention (ed RC O'Connor, J Pirkis): 220-40. Wiley Blackwell, 2016.

42 O'Connor RC, Rasmussen S, Hawton K. Distinguishing adolescents who think about self-harm from those who engage in self-harm. Br J Psychiatry 2012; 200(4): 330-5.

43 Dhingra K, Boduszek D, O'Connor RC. Differentiating suicide attempters from suicide ideators using the Integrated Motivational-Volitional model of suicidal behaviour. J Affect Disord 2015; 186: 211-8.

44 Klonsky ED, May AM. Differentiating suicide attempters from suicide ideators: a critical frontier for suicidology research. Suicide Life Threat Behav 2014; 44(1): $1-5$.

45 O'Connor RC, Kirtley OJ. The Integrated Motivational-Volitional Model of Suicidal Behaviour. Philos. Trans. Royal Soc. B. 2018; in press.

46 Platt S. Inequalities and suicidal behavior. In International Handbook of Suicide Prevention (ed RC O'Connor, J Pirkis): 258-83. Wiley Blackwell, 2016. 